\title{
Sensitivity of Process Parameters in Atmospheric Plasma Spray Coating
}

\author{
Biswajit Kumar Swain ${ }^{1}$ Soumya Sanjeeb Mohapatra ${ }^{2}$ Ashutosh Pattanaik ${ }^{3}$. \\ Sumant Kumar Samal ${ }^{1} \cdot$ Subrat Kumar Bhuyan ${ }^{1}$ Kasinatha Barik ${ }^{4}$. \\ Deepak Kumar Sahoo ${ }^{5} \cdot$ Ajit Behera $^{1}$
}

\author{
${ }^{1}$ Department of Metallurgical \& Materials Engineering, National Institute of Technology, Rourkela, India. \\ ${ }^{2}$ Department of Chemical Engineering, National Institute of Technology, Rourkela, India. \\ ${ }^{3}$ Department of Mechanical Engineering, C.V.Raman College of Engineering, Bhubaneswar, India. \\ ${ }^{4}$ Department of Chemical Engineering, Indira Gandhi Institute of Technology, Sarang, India. \\ ${ }^{5}$ State pollution control board, Govt. of Odisha, Rourkela, India.
}

\section{ABSTRACT}

Atmospheric plasma spraying (APS) is one of the most widely used thermal spraying technique which finds a lot of applications due to its versatility of spraying a wide range of materials from metallic to nonmetallic and hence more suitable for spraying of high melting point materials like refractory ceramics material, cermets etc. In recent era,any material can be used for plasma spraying on almost any type of substrate. Process parameters are the key factor that affects the formation of microstructures, bonding of coating with substrate and mechanical strength of coating. In this paper, the process parameters and their sensitivity towards the plasma modified structural elements are discussed.The microstructure of thermally sprayed coatings, which results from the solidification and sintering of the particles, frequently contain pores, oxides and cracks. The amount and distribution of these defects, as well as other coating properties as for instance thickness, hardness and bond strength, will be defined by the selected spray parameters. Therefore, the correct choice of the spray process as well as respective parameters (particle size, particle velocity, spray distance, plasma gun power, working pressure, substrate roughness, substrate temperature and so on) is very important for the deposition of good coatings and, consequently, to enlarge the useful life in service of the components.

(C) 2018 JTSE and INScienceIN. All rights reserved
ARTICLE HISTORY

Received 15-01-2018

Revised 31-01-2018

Accepted 01-02-2018

Published 06-04-2018

\section{KEYWORDS}

Plasma Spraying

Gun Power

Powder Size

Phase Composition

Substrate Temperature

\section{Introduction}

Plasma is an electrically conductive gas containing electrically charged particles, ions and electrons. In plasma spraying process, metals, alloys, high melting-point materials, such as ceramics and cermets in powder or wire form are melted and sprayed onto the subjects by using plasma jet as its heat source over $1000^{\circ} \mathrm{C}$. Plasma spraying has two type of methods APS which is carried out in the atmosphere, and VPS, carried out in the vacuum. APS process has a wide range of material choice and high level of adhesiveness. APS coating with advanced features as well as all-out quality control is widening its application fields. APS deposition is widely used since the beginning of 1980s. APS is one of the most versatile and rapid techniques to deposit protective overlay coatings onto the surface of components to increase their in-service properties especially under severe conditions [1-5]. APS has been widely used in different industries as given in table 1, due to their good mechanical properties and corrosion resistance [6-8]. APS coating materials widely used in the cathodic protection of steels are aluminum, zinc, $\mathrm{ZnAl}$ and AlMg alloys [9].

The main plasma spraying operating parameters that have an influence on deposition phenomenon are: the plasma gun power, primary gas in plasma chamber, carrier gas, working pressure, powder size, powder injection Angle, powder phase composition, substrate roughness, and substrate temperature are discussed in this paper.
Table 1: Typical applications of APS in different industries

\begin{tabular}{ll}
\hline Aerospace & Gas Turbine and Airframe components [10] \\
\hline Marine & Anti-fouling coating, anti-skid decking, \\
& propellers, shaft [11] \\
Electronics & RF shielding, insulators[12] \\
MEMS & silicon chip production equipment [13] \\
Automotive and & Engine and drive train components, mould \\
transportation & release coating [14] \\
Textile machinery & Stretch-Tow Rollers, Thread Guides [15] \\
Power generation & Gas turbine components and cases, \\
& hydroelectric turbine components, steam \\
& turbine components, solid oxide fuel cells [16] \\
Petrochemical & Pump components, valves, tank linings [17] \\
Pulp, paper and & Anilox rolls, impression rolls, corona rolls, \\
printing & boilers, digesters, paper manufacturing rolls \\
machinery & and components [18] \\
Metal processing & Sink rolls, extrusion rolls, extrusion dies [19] \\
Biomedical & Orthopedic implants [20] \\
Cutting tool & Steel cutting tool, non-steel cutting tool \\
& equipment [21] \\
Nuclear & Reactor equipment [22]
\end{tabular}

\section{Effect of plasma gun powder}

Optimum gun power is required to enhance the deposition efficiency. With small current, the energy density of plasma flame is low, only smaller powder is molten or partially-molten, larger size powder has little positive effect on deposition efficiency (DE) and inter-particle porosity increases. With increasing spraying current, the percentage of molten or semi-molten powder particle tends to increase, but the smaller size powder tends to vaporize at the time which affects the density by 
formation of interlayer pore. With the current increasing further, more and more larger size particles become molten or semi-molten, the vaporized smaller size powder is finite, contributing to higher DE. That is why the coating thickness going to thicker. larger spraying power also produce splash at the time of impact on the substrate surface, resulting in further mass loss and decrease in deposition efficiency [23]. By increasing the current, the temperature of process increased (the current and gas volume supplied to the plasma arc significantly affect the thermal content of plasma gas and heat transfer to the sprayed powder). Therefore, more particles were melted, and hence high adhesion strength and high hardness of coatings was produced [24].A low level in power may result in high porosity, whereas too much power may lead to high residual stresses, in which both factors gave negative effects on the microhardness [25].

\section{Effect of primary gas in plasma chamber}

Optimization of plasma gas mixture has a great importance to decrease plasma temperature that becomes only enough to melt the droplet just before impinging on substrate surface. In addition, enthalpy of commonly-seen gas used in plasma spraying ranks $\mathrm{Ar}<\mathrm{Ar}+\mathrm{He}<\mathrm{Ar}+\mathrm{H}_{2}<\mathrm{N}_{2}<\mathrm{N}_{2}+\mathrm{H}_{2}$ inorder [26]. Nitrogen is a general purpose primary gas used alone or with hydrogen secondary gas. Nitrogen also benefits from being the cheapest plasma gas. Nitrogen tends to be inert to most spray material except materials like titanium. Argon is probably the most favored primary plasma gas and is usually used with a secondary plasma gas (hydrogen, helium and nitrogen) to increase its energy. Argon is the easiest of these gases to form plasma and tends to be less aggressive towards electrode and nozzle hardware. Most plasma is started up using pure argon. The secondary gas hydrogen gas dramatically effects heat transfer properties and acts as anti-oxidant. Small amount of hydrogen added to the other plasma gases dramatically alters the plasma characteristics and energy levels and is thus used as one control for setting plasma voltage and energy. Helium is also used as a secondary gas with argon [27]. Helium is a noble gas and is completely inert to all spray materials and is used when hydrogen or nitrogen secondary gases have deleterious effects. Helium imparts good heat transfer properties and gives high sensitivity for control of plasma energy. It is commonly used for high velocity plasma spraying of high quality carbide coatings where process conditions are critical. The main gas and secondary gas were argon and hydrogen, respectively. Argon was monatomic gas without concentrating enthalpy value. Argon absorbed the heat and decomposed into monatomic form afterward ionized as the temperature increased. The nitrogen feeding gas contributed to there was no reaction between the melted powder and the environmental atmosphere. Argon is a primary gas, it cause rapid heat transfer rate between a plasma jet flame and the heated object, in addition it protects powder particles against oxidation while hydrogen is an auxiliary gas to increase plasma voltage; which lead to increase in plasma enthalpy and heat transfer rates [28-29] therefore, higher plasma gas heat capacity resulted.

\section{Effect of carrier gas}

The carrier gas is necessary to achieve appropriate particle injection adding to the momentum and energy at the control volumes that contain the side injector nozzle exit plane. The understanding of carrier gas effects on plasma jet and particle behavior is desirable for the control and designs of plasma spray process [30].Nearly all applications, the carrier gas is of relatively high density, such as argon or nitrogen. Particles in the high carrier gas flow rate experience a steep acceleration when entrained into the hot core of the plasma jet, but it will slow down at the peripheral areas of the plasma jet. By increasing carrier gas flow rate, the radial velocity increases at the centerline. The injection of carrier gas results in the deflection of the plasma jet and such deflection is aggravated by the increasing carrier gas flow rate. As a result, the flow change will directly affect the particle velocity and trajectory after leaving the injector exit.The optimum mass flow of carrier gas depends on the injector diameter and location, the plasma jet momentum and the density, and the particle size distribution of the feed powder. The particle evaporation and fusion contribute to the weak influence of carrier gas flow rate on the particle temperature [31].The particle spray pattern is greatly influenced by the carrier gas flow rate, while particle temperature and velocity is not sensitive to it. Fine particles and especially those of lowdensity material require a high carrier gas flow rate to impart the appropriate velocity at the injection point.At low carrier gas flow rates, the deviation of the particle trajectory from the jet axis increased almost linearly with gas flow rate.In the case of internal injection of the powder in the nozzle anode, the flow rate can induce a relatively high deviation of the plasma jet under conditions where the carrier gas exceeds $10 \%$ of the plasma gas mass flow rate [32].In the case of external injection, the carrier gas effect on the plasma jet is negligible. For a given carrier gas flow rate, the particle velocity at the injector exit is nearly independent of particle size; therefore, the finer particles may have insufficient momentum to penetrate the plasma jet and thus bypass it. The above bypass effect is more marked with injectors of larger diameter. For injectors of the same diameter, the carrier gas flow rate must be increased when using a curved injector, as compared to a straight one. The sharper is the curvature radius; the greater must be the carrier gas flow rate [33].

\section{Effect of powder size}

The particle size affects the deposition, solidification, and crystallization of molten droplets by influencing the size of deposited particles, thus affecting the microstructure of the coatings. The coating prepared from the fine powder shows a well adhered splat with a few inter-lamellar pores. The coatings performed from the coarse powder on the other hand show poorly adhered splats and a significant number of large pores. This is due to the existence of fragmented splats with poor splat-to-splat contact at larger interlamellar pores [34]. Fine particles typically result in good melting during deposition, and further the low porosity for coatings due to the decreased volume of inter-splats gaps and voids [35]. Correspondingly, the coatings deposited from fine powder exhibit higher fracture toughness compared to the coating deposited from coarse powder. Coatings prepared by coarse YSZ powder tend to form almost the same number of horizontal and vertical pores, while coatings prepared by fine powder tend to form horizontal ones parallel to the substrate [36]. As the pore orientation changes from horizontal to vertical, the maximum stress shows a decreasing trend both during the insulation stage and the quenching process flattening and 
fragmentation are affected by the particle condition before impact, and higher velocities and temperature result in fragmented splats and in greater bonding to substrate. In principle, fine particles are accelerated more quickly by the gas stream and spend a shorter time in high-temperature regions. The particle temperature depends on both the surrounding plasma temperature and the dwell time of the particles in the flame. The feedstock particles of larger size results in the formation of rougher coating surface, which is in accordance with the works of Reisel [28]. The Oxygen content of the coating increases with a decrease in the particle size. The void content of the coating increases with the increase of particle size and the microhardness decreases with increasing particle size. The spherical particles observed on the surface of the coatings are believed to be redeposited droplets formed by "splashing" of the spray particles upon surface impact contains some microcracks, which are supposed to be caused by the internal residual stresses during the spraying process [37].

\section{Effect of powder flow rate}

Thickness/cycle was highly affected by the powder feed rate. A high scanning speed shortened the deposition time. Thus, a high feed rate with low scanning speed worked best to obtain the optimum thickness/cycle. It is expected that by increasing the powder flow rate, rate of deposited material increased. Therefore, the hardness and deposition efficiency of coating increased [38].

\section{Effect of working pressure}

The plasma spray process is most commonly used in normal atmospheric conditions and referred as APS. Some plasma spraying is conducted in protective environments using vacuum chambers normally back filled with a protective gas at low pressure; this is referred as VPS or LPPS. High-pressure plasma spraying was found to be suitable for thermal spraying of high-melting-point materials such as zirconia [39-40].

\section{Effect of powder phase composition}

The powder phase composition as well as the molten degree of feedstock powder is affected by the spraying power. The phase stability mainly results the final microstructure and properties of the material [41].The limited phase stability, sintering also reduces the hightemperature capability, as it leads to a loss of strain tolerance of the coatings and hence early failure. Phase transformation occurs during plasma spraying of any materials. That is: the phase transformation in $\mathrm{Al}_{2} \mathrm{O}_{3}$ coating is $\alpha-\mathrm{Al}_{2} \mathrm{O}_{3}$ to $\gamma-\mathrm{Al}_{2} \mathrm{O}_{3}$. In AT3 coating, it is $\alpha-\mathrm{Al}_{2} \mathrm{O}_{3}$ and rutile $\mathrm{TiO}_{2}$ to $\gamma-\mathrm{Al}_{2} \mathrm{O}_{3}$ and anatase $\mathrm{TiO}_{2}$. $\mathrm{TiO}_{2}$ will inhibit the transformation from $\alpha-\mathrm{Al} 203$ to $\gamma$-Al203, and with the increase of its content, the degree of inhibition is enhanced [42].

\section{Effect of Spray Distance (Stand-off-distance)}

The spray distance affects the droplet temperature and thus the properties of spray coatings. Optimum stand-offdistance is important to ensure good adherence of coating with the substrate. Too short spraying distance will produce lower adherence due to overheating and resulting excessively molten particles to splash, creating a less dense coating, internal stress inside the coating. In contrast, too long spraying distance will decrease the adherence bonding due to cooling and deceleration of the particles flying in the plasma beam [43]. For coarsegrained feedstock longer spraying distances is required. It is believed that longer spraying distance provided sufficient time for the powder to dwell and melt properly and hence produced higher coating efficiency. As the spray distance increases the number of droplets which impact normally decrease because deviation occurs for the droplet during flight for a long distance and the hardness value decreased, also the atmospheric oxygen incorporated with splats during impinging affect the properties of the coating because they create a kind of stress points [44]. The deviation of the spray distance from the optimum condition leads to increase the porosity, pullout, un-melted particles and de-laminations that lead to lower corrosion efficiency.

\section{Effect of spraying angle}

The thermally sprayed coatings show a clear dependence on the spray angle. The spray angle in a thermal plasma spraying system is the angle between the axis of plasma jet and surface of substrate in plane orthogonal to plasma jet displacement. At $90^{\circ}$ the sprayed particles exhibit a tangential component with respect to the substrates surface. Angle smaller than $90^{\circ}$ leads to increase in probability to bounce off the sprayed particles. A decrease in spray angle changes the thickness, width, and form of the spray beads. The coatings become rougher and their quality decreases. Kang et al. describe the decline in coating thickness at smaller spray angles with a decrease of the normal component of the particle velocity regarding the substrates surface [45]. Lower spray angles lead to increase in porosity (e.g. WC-12Co coatings). A decrease in spray angle results in a reduction of the normal component and provides a benefit to the tangential component of the spray particles regarding the substrates surface. An increase in the tangential component results in a higher probability that particles bounce off from the surface of the substrate. Therefore, the deposition efficiency declines. Particularly, the tensile strength of the WC-12Co coating is strongly influenced by the spray angle. The coatings sprayed with an angle of $90^{\circ}$ delaminated during the tensile tests at the interface between substrate and coating. A decrease in spray angle resulted in an increased probability of a mixed fracture composed of interfacial and cohesive failure. At $30^{\circ}$ all coatings failed cohesively. This behavior is due to the rough coating microstructure at smaller spray angles and especially at 30 caused by the high porosity of the coatings. As the injector angle decreases from $90^{\circ}$ to the lower value of 600 , the hardness decreased from 200 to 187 HVand the porosity increased from $9.8 \%$ to $13.8 \%$. This may be referred to the poor contact to previous coating at interface. The maximum recirculating velocity also increases as spray angle decreases [46].

\section{Effect of substrate roughness}

Moreover the adhesive strength of a thermally sprayed coating is greatly influenced by the surface roughness of the substrate. In industrial applications the substrates are usually roughened in order to achieve good adhesion by mechanical interlocking. In order to get coatings with high adhesive strength, it is essential to investigate how the surface roughness influences the flattening of droplets. In the most practical cases, grit blasting of the substrate surface is essential in order to achieve coatings with good adhesion to the substrate [47]. When there is increase in 
temperature of roughened substrates, there is decrease in splashing. In the case of metallic droplets sprayed onto a stainless steel substrate, the nanometric scale roughness of the substrate, caused by preheating, resulted in better wetting thus better flattening behavior of the droplet. However, an extremely increased roughness of substrate can promote the splashing and/or the oxidation of splats. In contrast, the droplet impact on substrates with smaller roughness is characterized by more splashing as the liquid tends to jet out under the influence of its momentum [48].

\section{Effect of substrate temperature}

Primarily the thermal distortion can be prevented by increasing he substrate temperature during plasma spraying. The preheat substrate temperature has effect on the morphology of the droplet (splat) and the properties of the deposits. Coating properties are therefore highly dependent on fluid flow and heat transfer during droplet impact and are affected by surface temperature. For typical spraying conditions substrate temperatures are several hundred degrees and the thermal conductivities are actually similar for both substrate materials at these temperatures. It was reported that the high temperature substrates yield well layered lamellae whereas low temperature substrates display deposits in disarray, containing the small particles which are the products of the fragmented splat. The fragmented particles formed on low temperature substrates evolve into structures which display greater porosity than those deposits formed on high temperature. At higher temperature, less trapped gas in the air pocket underneath the splats will result in less chance of splashing and due to the expansion of the air pocket upon heating by the droplet or a smaller pore when the deposit is cooled down [49]. The same starting particle size distribution for the high substrate temperature indicates that a greater portion of the splat is intact, corresponding to a larger contiguous area. As a consequence, interlamelar porosity with enhanced interfacial contact is reduced. Substrate temperature has also a far more influencing effect on coating hardness. The high substrate temperature is caused on the high packed coatings in comparison to the low substrate temperatures and increased the hardness of coating. The resulting deposits may be induced by altering the original chemical composition [50]. Phase changes in coatings on the substrate depend on the cooling rate the flattening droplets and on the substrate temperature [51]. However, a large thermal mismatch may be generated between coating and substrate with the variation of temperature. This large thermal mismatch will cause a large thermal residual stresses which will result in the formation of cracks or spallation of the coatings the thermal expansion also gradually enhances with temperature for all coatings. Delaying solidification, either by raising surface temperature or in-creasing thermal contact resistance at the droplet-substrate interface, is expected to suppress splashing. Coating adhesion strength is seen to increase with substrate temperature [52].

\section{Effect of Substrate cooling}

The substrate temperature was varied by cooling the back surface of the Substrate during Spraying with a jet of compressed air. The substrate temperature during deposition was monitored by a thermocouple attached to the back surface of the substrate. The cooling must be slowly in order to avoid micro-cracking, the increase in temperature of the work piece depends on the use of cooling, distance between torch and work piece, type of plasma gas, amount of plasma gas, the amount of powder, and heat energy leaving the plasma torch [53]. Reduce the cooling rate of particles impinging on the surface, giving them more time to flow into surface cavities and form stronger bonds [54]. A possible mechanism for the generation of segmentation cracks is that they are created when the sample is cooled to room temperature, after the deposition process is complete, as are sult of relaxation of bi-axial stresses.

\section{Effect of environment}

The plasma spraying process is most commonly used in normal atmospheric conditions and referred as APS. Nitrogen tends to be inert as a primary gas in most spray material except materials like titanium [55]. Argon is a noble gas and is completely inert to all spray materials. Some plasma spraying is conducted in protective environments. In reactive plasma spraying, the plasma spray process has done through the required reactive gas. The vacuum chambers normally back filled with a protective gas at low pressure, this is referred as VPS or LPPS.

\section{Effect of nozzle length}

The long anode nozzle could improve the melting of the powders and deposition efficiency, and enhance the coatings' hardness. At the same time, the long anode nozzle could lead to a decrease in the overspray phenomenon. The long anode nozzle could increase the electron temperature and improve the energy of the plasma jet. Due to the higher temperature in the external plasma jet and longer dwelling time of the powder particles inside the long nozzle, the long anode nozzle can make the powder particles heated more efficiently and better evaporated. A converging-diverging long anode nozzle was designed for the following reasons: the converging-diverging anode nozzle has the potential to produce supersonic flows, which can improve velocity of the plasma jet; the extended anode nozzle can enhanced plasma jet energy density; the particles can be melted well due to the longer dwelling time in the plasma jet [56].

\section{Conclusions}

The process parameters are greatly affects the plasma sprayed material properties that can be conclude as-

The microhardness and the thickness of the coating were strongly affected by the power of the plasma. Thickness/cycle was highly affected by the powder feed rate. Deposition efficiency increases with the increase of spraying current. There is a general tendency that deposition efficiency firstly increases and then decreases with the increase of spraying current. The increase of the substrate temperature was enhanced the hardness and reduced the porosity. Coating porosity decreased with increasing substrate temperature.The velocity and temperature of in-flight particles increased with decreasing the particle size. Spray angles have significant effects on recirculating flow structure in the plasma spray torch due to the different degree of flow impendence resulting from the substrate inclination in different spray angle cases. As the injection angle decreases or as the injection distance increases led to increase the porosity, decrease the droplet temperature and decrease the number of droplets which impact normally. 


\section{References}

1. https://www.tocalo.co.jp/english/technical/aps.html, 28.12.2017

2. https://www.tocalo.co.jp/e_tech_vps.html, 28.12.2017

3. http://www.gordonengland.co.uk/xpft.htm, 28.12.2017

4. Azarmi F, Coyle TW, Mostaghimi J. Optimization of atmospheric plasma spray process parameters using a design of experiment for alloy 625 coatings. Journal of Thermal Spray Technology. 2008 Mar 1;17(1):144-55.

5. Guo HB, Vaben R, Stover D. Atmospheric plasma sprayed thick thermal barrier coatings with high segmentation crack density. Surface and Coatings technology. 2004 Sep 1;186(3):353-63.

6. Wang Y, Coyle TW. Optimization of solution precursor plasma spray process by statistical design of experiment. Journal of Thermal Spray Technology. 2008 Dec 1;17(56):692-9.

7. Pulpytel J, Kumar V, Peng P, Micheli V, Laidani N, Arefi-Khonsari F. Deposition of Organosilicon Coatings by a Non-Equilibrium Atmospheric Pressure Plasma Jet: Design, Analysis and Macroscopic Scaling Law of the Process. Plasma Processes and Polymers. 2011 Jul 22;8(7):664-75.

8. Azarmi F, Saaedi J, Coyle TW, Mostaghimi J. Microstructure characterization of alloy 625 deposited on nickel foam using air plasma spraying. Advanced Engineering Materials. 2008 May 1;10(5):459-65.

9. Schutze A, Jeong JY, Babayan SE, Park J, Selwyn GS, Hicks RF. The atmospheric-pressure plasma jet: a review and comparison to other plasma sources. IEEE transactions on plasma science. 1998 Dec;26(6):1685-94.

10. Heimann RB. Plasma-spray coating: principles and applications. John Wiley \& Sons; 2008 Jul 11.

11. Park E, Condrate RA. Graded coating of hydroxyapatite and titanium by atmospheric plasma spraying. Materials Letters. 1999 Sep 30;40(5):228-34.

12. Hui R, Wang Z, Kesler O, Rose L, Jankovic J, Yick S, Maric R, Ghosh D. Thermal plasma spraying for SOFCs: Applications, potential advantages, and challenges. Journal of Power Sources. 2007 Jul 10;170(2):308-23.

13. Kogelschatz U. Atmospheric-pressure plasma technology. Plasma Physics and Controlled Fusion. 2004 Nov 17; 46(12B):B63.

14. Roth JR. Industrial Plasma Engineering: Volume 2Applications to Nonthermal Plasma Processing. CRC press; 2001 Aug 25.

15. Tendero C, Tixier C, Tristant P, Desmaison J, Leprince P. Atmospheric pressure plasmas: A review. SpectrochimicaActa Part B: Atomic Spectroscopy. 2006 Jan 31;61(1):2-30.

16. Sampath $\mathrm{S}$. Thermal spray applications in electronics and sensors: past, present, and future. Journal of thermal spray technology. 2010 Sep 1;19(5):921-49.

17. Heimann RB. Applications of plasma-sprayed ceramic coatings. InKey Engineering Materials 1996 (Vol. 122, pp. 399-442). Trans Tech Publications.

18. Takemura Y, Yamaguchi N, Hara T. Study on surface modification of polymer films by using atmospheric plasma jet source. Japanese Journal of Applied Physics. 2008 Jul 11;47(7R):5644.

19. Pawlowski L. The science and engineering of thermal spray coatings. John Wiley \& Sons; 2008 Apr 30.

20. Kurunczi PF, inventor; Cerionx, Inc., assignee. Atmospheric pressure non-thermal plasma device to clean and sterilize the surfaces of probes, cannulas, pin tools, pipettes and spray heads. United States patent US 7,094,314. 2006 Aug 22.

21. Park GY, Park SJ, Choi MY, Koo IG, Byun JH, Hong JW, Sim JY, Collins GJ, Lee JK. Atmospheric-pressure plasma sources for biomedical applications. Plasma Sources Science and Technology. 2012 Jun 6;21(4):043001.

22. Selwyn GS, Herrmann HW, Park J, Henins I. Materials processing using an atmospheric pressure, RF-generated plasma source. Contributions to Plasma Physics. 2001 Nov $1 ; 41(6): 610-9$.
23. Sreekumar KP, Karthikeyan J, Ananthapadmanabhan PV, Venkatramani N, Chatterjee UK. Plasma spray technology process parameters and applications. BARC-1551. 1991.

24. Wang YJ, Xu JY, Zhao QH, Wang Y, Gao B. Effects of various power process parameters on deposition efficiency of plasma-sprayed $\mathrm{Al} 203-40 \%$ wt. $\mathrm{TiO} 2$ coatings. InIOP Conference Series: Materials Science and Engineering 2017 Jun (Vol. 213, No. 1, p. 012042). IOP Publishing.

25. Sahab AR, Saad NH, Kasolang S, Saedon J. Impact of plasma spray variables parameters on mechanical and wear behaviour of plasma sprayed $\mathrm{Al} 2 \mathrm{O} 3$ 3\% wt TiO2 coating in abrasion and erosion application. Procedia Engineering. 2012 Jan 1;41:1689-95.

26. Forghani SM, Ghazali MJ, Muchtar A, Daud AR, Yusoff NH, Azhari CH. Effects of plasma spray parameters on TiO 2coated mild steel using design of experiment (DoE) approach. Ceramics International. 2013 Apr 30;39(3):31217.

27. Morsi MS, El Gwad SA, Shoeib MA, Ahmed KF. Effect of air plasma sprays parameters on coating performance in zirconia-based thermal barrier coatings. Int. J. Electrochem. Sci. 2012 Apr 1;7(4):2811-31.

28. https://idea.library.drexel.edu,05.01.2017.

29. Thirumalaikumarasamy D, Shanmugam K, Balasubramanian V. Effect of atmospheric plasma spraying parameters on porosity level of alumina coatings. Surface Engineering. 2012 Nov 1;28(10):759-66.

30. Adam Khan M, Sundarrajan S, Natarajan S. Influence of plasma coatings on Inconel 617 for gas turbine applications. Surface Engineering. 2014 Sep 1;30(9):656-61.

31. Zhang W, Zheng L, Sampath S. Effect of Injection Angle on Particles In-Flight Characteristics. In9th AIAA/ASME Joint Thermophysics and Heat Transfer Conference 2006 (p. 3826).

32. Xiong HB, Zheng LL, Sampath S, Williamson RL, Fincke JR. Three-dimensional simulation of plasma spray: effects of carrier gas flow and particle injection on plasma jet and entrained particle behavior. International Journal of Heat and Mass Transfer. 2004 Nov 30;47(24):5189-200.

33. Vardelle M, Fauchais P, Vardelle A, Li KI, Dussoubs B, Themelis NJ. Controlling particle injection in plasma spraying. Journal of Thermal Spray Technology. 2001 Jun 1;10(2):267-84.

34. Zhang W, Zheng LL, Zhang H, Sampath S. Study of injection angle and carrier gas flow rate effects on particles in-flight characteristics in plasma spray process: Modeling and experiments. Plasma Chemistry and Plasma Processing. 2007 Dec 1;27(6):701-16.

35. Kulkarni AA, Goland A, Herman H, Allen AJ, Ilavsky J, Long GG, De Carlo F. Advanced microstructural characterization of plasma-sprayed zirconia coatings over extended length scales. Journal of Thermal Spray Technology. 2005 Jun 1;14(2):239-50.

36. Li CJ, Ohmori A, Harada Y. Effect of powder structure on the structure of thermally sprayed WC-Co coatings. Journal of materials science. 1996 Jan 1;31(3):785-94.

37. Huang J, Wang W, Lu X, Hu D, Feng Z, Guo T. Effect of Particle Size on the Thermal Shock Resistance of PlasmaSprayed YSZ Coatings. Coatings. 2017 Sep 19;7(9):150.

38. Niu Y, Zheng X, Liu X, Ji H, Ding C. Influence of powder size on characteristics of air plasma sprayed silicon coatings. Ceramics International. 2012 Sep 30;38(7):5897-905.

39. Sahab AR, Saad NH, Kasolang S, Saedon J. Impact of plasma spray variables parameters on mechanical and wear behaviour of plasma sprayed $\mathrm{Al} 2 \mathrm{O} 3$ 3\% wt TiO2 coating in abrasion and erosion application. Procedia Engineering. 2012 Jan 1;41:1689-95.

40. http://engineershandbook.com/MfgMethods/thermalspray ing.htm

41. Bergmann CP, Vicenzi J. Protection against erosive wear using thermal sprayed cermet: a review. Springer Science \& Business Media; 2011 Jul 2.

42. Mauer G, Jarligo MO, Mack DE, Vaben R. Plasma-sprayed thermal barrier coatings: new materials, processing issues, 
and solutions. Journal of thermal spray technology. 2013 Jun 1;22(5):646-58.

43. Mauer G, Vaben R. Current developments and challenges in thermal barrier coatings. Surface engineering. 2011;27(7):477-9.

44. Khandanjou S, Ghoranneviss M, Saviz S. The investigation of the microstructure behavior of the spray distances and argon gas flow rates effects on the aluminum coating using self-generated atmospheric plasma spray system. Journal of Theoretical and Applied Physics. 2017 Sep 1;11(3):225-34.

45. Vinayo ME, Kassabji F, Guyonnet J, Fauchais P. Plasma sprayed WC-Co coatings: influence of spray conditions (atmospheric and low pressure plasma spraying) on the crystal structure, porosity, and hardness. Journal of Vacuum Science \& Technology A: Vacuum, Surfaces, and Films. 1985 Nov;3(6):2483-9.

46. Tillmann W, Vogli E, Krebs B. Influence of the spray angle on the characteristics of atmospheric plasma sprayed hard material based coatings. Journal of Thermal Spray Technology. 2008 Dec 1;17(5-6):948-55.

47. Kang CW, Ng HW, Yu M. Imaging diagnostics study on obliquely impacting plasma-sprayed particles near to the substrate. Journal of thermal spray technology. 2006 Jan 1;15(1):118.

48. Christoulis DK, Pantelis DI, Borit F, Guipont V, Jeandin M. Effect of substrate preparation on flattening of plasma sprayed aluminium bronze powders. Surface engineering. 2006 Dec 1;22(6):420-31.

49. Christoulis DK, Pantelis DI, Borit F, Guipont V, Jeandin M. Effect of substrate roughness and temperature on splat formation in plasma sprayed aluminium bronze. InSurface modification technologies XVIII 2006 (pp. 73-83). ManeyASM.

50. Sarikaya 0. Effect of some parameters on microstructure and hardness of alumina coatings prepared by the air plasma spraying process. Surface and Coatings Technology. 2005 Jan 21;190(2):388-93.

51. Sampath S, Jiang XY, Matejicek J, Leger AC, Vardelle A. Substrate temperature effects on splat formation, microstructure development and properties of plasma sprayed coatings Part I: Case study for partially stabilized zirconia. Materials Science and Engineering: A. 1999 Nov 15;272(1):181-8.

52. Chraska P, Dubsky J, Kolman B, Forman J. Study of phase changes in plasma sprayed deposits. Journal of Thermal Spray Technology. 1992 Dec 1;1(4):301-6.

53. Khor KA, Gu YW. Thermal properties of plasma-sprayed functionally graded thermal barrier coatings. Thin Solid Films. 2000 Sep 1;372(1):104-13.

54. Tsipas SA, Golosnoy IO. Effect of substrate temperature on the microstructure and properties of thick plasma-sprayed YSZ TBCs. Journal of the European Ceramic Society. 2011 Dec 31;31(15):2923-9.

55. Pershin V, Lufitha M, Chandra S, Mostaghimi J. Effect of substrate temperature on adhesion strength of plasmasprayed nickel coatings. Journal of Thermal Spray Technology. 2003 Sep 1;12(3):370-6.

56. Latreche H. Development of protective coatings to improve high temperature corrosion resistance in chlorine containing environments based on an advanced corrosion risk assessment tool (Doctoral dissertation, Aachen, Techn. Hochsch., Diss., 2009).

57. Sun C, Gao Y, Yang D, Fu Y. Effects of the nozzle design on the properties of plasma jet and formation of YSZ coatings under low pressure conditions. Chinese Journal of Mechanical Engineering. 2016 Sep 1;29(5):954-61. 